5. Lantz PM, Mendez D, Philbert MA. Radon, smoking, and lung cancer: the need to refocus radon control policy. Am J Public Health 2013;103:443-7.

6. Denman AR, Phillips PS, Coskeran T, et al. Carefully targeted radon reduction strategies are more appropriate [letter]. BMJ 2009;338:a3110. Available: www.bmj.com/rapid-response/2011/11/02/ carefully-targeted-radon-reduction-strategies-are -more-appropriate (accessed 2015 June 30).

CMAJ 2015. DOI:10.1503/cmaj.1150064

\section{The art of medicine}

In their CMAJ essay, Whitehead and Kuper ${ }^{1}$ rightly note that dichotomizing medical teaching and practice into "science" and "art" is unhelpful and misleading. Montgomery ${ }^{2}$ compares the science-art dichotomy to the wave-particle duality of light and argues that the term "art" is used to capture that which seems to defy scientific study, such as clinical judgment and bedside manner.

If we compare the art and science of medicine to the wave-particle duality of light, the science of medicine perhaps seems like the particle: solid, tangible, weighty, circumscribed. Meanwhile, the art seems like the wave: ethereal, intangible, elusive and ineffable. Ethereal things seem less real, like the luminiferous ether at the root of the word. When, near the end of the 19th century, Michelson and Morley set out to measure the ether, they discovered that it wasn't really there. ${ }^{3}$ The ethereal image of clinical judgment is reinforced by voluminous research concluding that "mechanical predictions" (made using scientific rules or algorithms) consistently outcompete "clinical predictions" (made on the basis of clinical judgment). ${ }^{4}$

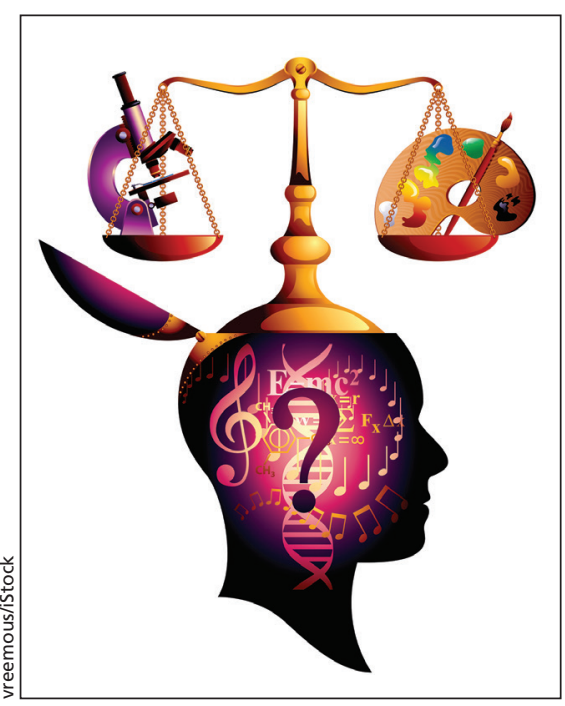

On the other hand, the conception that the art of medicine is intangible, elusive and ineffable is reinforced by the presumption that it is unresearchable and unteachable. Art is creative genius, not to be disturbed. Such an attitude adopts a narrow view of scientific research as consisting in basic science and clinical epidemiology. As a philosophy graduate student and a medical student, I've learned that clinical judgment involves formal and informal reasoning, values, intuition and assumptions. All these components fall under the purview of philosophical study as well as scientific study, broadly construed to include not only basic science and clinical epidemiology, but also logic and the social sciences and humanities (including psychology, history and sociology).

Rather than denigrate clinical judgment and other components of the art of medicine as unscientific or exalt them as creative genius, we must teach them rigorously, and just as importantly, research them rigorously. Otherwise, like a light wave they will dissipate before our eyes.

\section{Jonathan Fuller}

Faculty of Medicine, University of Toronto, Toronto, Ont.

\section{References}

1. Whitehead C, Kuper A. A false dichotomy. CMAJ 2015;187:683-4.

2. Montgomery K. How doctors think: clinical judgment and the practice of medicine. New York: Oxford University Press; 2006.

3. Kuhn T. The structure of scientific revolutions. Chicago: University of Chicago Press; 1996.

4. Grove WM, Zald DH, Lebow BS, et al. Clinical versus mechanical prediction: a meta-analysis. Psychol Assess 2000;12:19-30.

CMAJ 2015. DOI:10.1503/cmaj.1150065

\section{Long-term use of diphenhydramine}

The review article in CMAJ by McMillan and colleagues concluded that there is a paucity of long-term safety and efficacy data for the use of non-benzodiazepine sedative-hypnotics such as diphenhydramine. ${ }^{1}$

A recently published prospective cohort study reveals a higher cumulative strong anticholinergic use is associated with an increased risk for dementia. ${ }^{2}$ Anticholinergics include tricyclic antidepressants, bladder antimuscarinics and first generation antihistamines.
Harvard Health Blog brings attention to this study linking the common anticholinergic drug Benadryl to increased dementia risk. ${ }^{3}$

In addition to being a non-benzodiazepine sedative-hypnotic, Benadryl is also used as an antihistamine.

Benadryl may contain different antihistamines. In Vancouver, it is diphenhydramine; in London, United Kingdom, it is cetirizine; in Cophenhagen, Denmark, it is acrivastine.,

Benadryl-containing diphenhydramine is available in a number of countries worldwide including the United States, Canada, Singapore, Taiwan, Italy, Hong Kong and others. However, diphenhydramine is a banned substance in Zambia.

Patients should check the ingredients instead of relying on the brand name. Caution should be exercised for long-term use of Benadryl (diphenhydramine), an antihistamine and a non-benzodiazepine sedative-hypnotic, because of the association of increased risk for dementia.

\section{H.C. George Wong MD}

Clinical Professor, Division of Allergy and Immunology, Department of Medicine, University of British Columbia,

Vancouver, BC

\section{References}

1. McMillan JM, Aitken E, Holroyd-Leduc JM. Management of insomnia and long-term use of sedative-hypnotic drugs in older patients. CMAJ 2013;185:1499-505.

2. Gray SL, Anderson ML, Dublin S, et al. Cumulative use of strong anticholinergics and incident dementia: a prospective cohort study. JAMA Intern Med 2015;175:401-7.

3. Merz B. Common anticholinergic drugs like Benadryl linked to increased dementia risk. Cambridge (MA): Harvard Health Blog; 2015 Available: www. health.harvard.edu/blog/common-anticholinergic -drugs-like-benadryl-linked-increased-dementia -risk-201501287667 (accessed 2015 July 1).

4. Wong HCG. Different antihistamines with the same brand name sold in different countries [poster]. European Academy of Allergy and Clinical Immunology Congress; 2015 June 6-10; Barcelona, Spain.

5. Wong HCG. Not all Benadryl are the same. [letter]. BCMJ 2015;57:229.

CMAJ 2015. DOI:10.1503/cmaj.1150066

\section{Letters to the editor}

Letters have been abbreviated for print. See www.cmaj.ca for full versions and competing interests. 